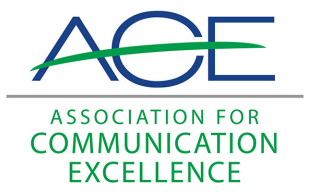

Journal of Applied Communications

\title{
Visual Special Effects in Instructional Video Programs and Their Impact on Adult Learning: A Review of the Literature
}

Edrle L. Greer

Chlere Campbell Gibson

Follow this and additional works at: https://newprairiepress.org/jac cc) (ㅇ)

This work is licensed under a Creative Commons Attribution-Noncommercial-Share Alike 4.0 License.

\section{Recommended Citation}

Greer, Edrle L. and Gibson, Chlere Campbell (1994) "Visual Special Effects in Instructional Video Programs and Their Impact on Adult Learning: A Review of the Literature," Journal of Applied Communications: Vol. 78: Iss. 3. https://doi.org/10.4148/1051-0834.1412

This Research is brought to you for free and open access by New Prairie Press. It has been accepted for inclusion in Journal of Applied Communications by an authorized administrator of New Prairie Press. For more information, please contact cads@k-state.edu. 
Visual Special Effects in Instructional Video Programs and Their Impact on Adult Learning: A Review of the Literature

\section{Abstract}

Television is a pervasive part of nearly every American's life. 


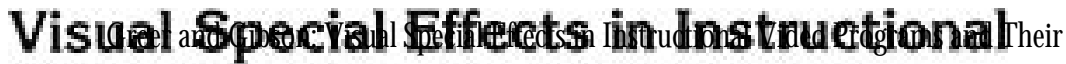 Video Programs and Their Impact on Adult Learning: A Review of the Literature}

\section{Edrie L. Greer Chere Campbell Gibson}

Protection against stimuli is an almost more important function for the living organism than reception of stimult.-Sigmund Freud

Television is a pervasive part of nearly every American's life. According to Condry (1989), television is not only a device but a powerful industry. Part of that industry is educational programming. As a video producer and instructional designer, the lead author has noted a growing tension surrounding the production of instructional television programs. Often, there may be tradeoffs between aesthetically pleasing and innovative programming and effective instruction. Educational television producers are traditionally trained to emulate broadcast entertainment television, and critical acceptance by peers is generally bestowed on programs with aesthetic value, sometimes in spite of only superficial attention paid to meeting instructional objectives.

\section{Introduction}

By 1985 more than $99 \%$ of continental U.S. homes owned at least one television set, and the average person was watching approximately four hours of television per day (Condry 1989). That viewing includes only the major television networks and cable, with their

Edrie L. Greer, a former ACE Member, is a program specialist in Telecemmunications/Electronic Distance Learning in the Division of Continuing Education and Summer School, East Carolina University, Greenville, North Carolina. Chere Campbell Gibson is an Associate Professor in the Department of Continuing and Vecational Education at the University of Wisconsin-Madison. 


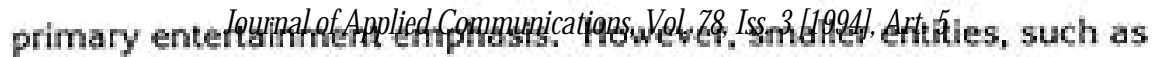
hospitals, universities, community colleges, governments, and corporations, are also using the medium for information dissemination, teaching, and training (Brush, 1993; Geber, 1990).

If a viewer watches an educational program but finds it dull or lacking in some way, $\mathrm{s} / \mathrm{he}$ may find it difficult to pay attention. Therefore, producers and designers of instructional video need to determine how best to design programs to attract and maintain viewer interest while increasing learning and comprehension. Wurman (1989) described the problem of emphasis on appearances in the publications industry:

Despite the critical role that graphic designers play in the delivery of information, most of the curriculum in design schools is concerned with teaching students how to make things look good. This is later reinforced by the profession, which bestows awards primarily for appearance rather than for understandability or even accuracy. There aren't any Oscars, Emmys, or Tonys for making graphics comprehensible (p. 56).

One of the primary means by which television producers add aesthetic value to their programs is through the use of production techniques, or production variables. The study of television production variables is known as television aesthetics (Wood, 1984).

Production techniques capitalize on the various capabilities of television to communicate via visual, aural, and textual channels (Hanson, 1989). Visual production techniques include editing and sequencing, composition, lighting, and camera and subject movement, and are also known as formal or structural features (Condry. 1989). In general, adding more or increasingly complicated production techniques tends to augment the "production values" of a particular program-its overall aesthetic appeal. Some have argued that such techniques are crucial to the success of instructional programs and can be manipulated by producers to attract attention and achieve maximum learning (Walker, 1987; Whiting, 1988). Others (Gayeski, 1991) maintained that many broadcast methods are not applicable to instructional and corporate video.

To date, there has been a great deal of research about the effects of instructional television on individuals, particularly children (Condry, 1989). Little research, however, has been devoted to investigating thoroughly the production techniques that are used by television producers and instructional designers in the production of instructional television programs for adults (Drew $\varepsilon$ Cadwell, 1985).

Much of what television producers are taught about production techniques is based on conjecture and little else (Harder, 1985). Researchers need to provide producers with practical, but theoreti- 
Greer and Gibson: Visual Special Effects in Instructional Video Programs and Their cally-based information on how these production variables can be manipulated to reach instructional objectives. And this research should come from a variety of fields: instructional design, adult education, cognitive and behavioral psychology, communications and information systems theory, computer graphics, aesthetics, and the fine arts (Abed, 1988; Metallinos, 1991; Seels, 1989).

\section{Purpose}

The purpose of this literature is to examine the impact on learning of one type of production variable: visual special effects in television programs designed for adults. in a practical sense this variable is important to producers because these effects are used frequently in instructional production and often require a significant amount of time and money to produce (McCartney, 1990).

There is a concem among some educators, however, that video effects may not augment learning (Ginsburg. Bartels, Kleingunther $\&$ Droege, 1988). What matters most in an instructional video is that learning takes place and not that the pictures are necessarily pretty. although nothing is wrong with achieving both, if enough resources (i.e. skilled and talented graphic artists and producers, specialized equipment, and sufficient time/money) are available. The point is that too often sufficient resources are not available. In the end, if a choice must be made, substance is more important than form in achieving learning objectives. And achieving learning objectives is the heart of instructional systems design (Shiffman, 1986).

It is vital that producers and purchasers of graphic equipmenteven the less-expensive desktop video and multi-media systems (which can be used to design graphics on conventional personal computers and are mostly software-based)-thoroughly assess whether the additional effects that can be created are worth the extra cost and/or time. Time spent on designing visual effects might be better allocated to improving scriptwriting and instructional design.

This literature review is designed to provide a framework from which to investigate these questions and help video producers and instructional designers begin to make proper decisions about when to use visual special effects in their instructional programs.

\section{Defining Visual Special Effects}

Before continuing, the term "visual special effect" should be defined. Video and television visual special effects are "imagemanipulation techniques primarily created during the on-line [final] editing process" (Smith, 1991, p. 346). The author uses this term to include cuts and dissolves. (A cut is an instantaneous change from 


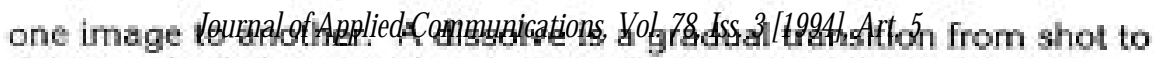
shot, in which the two images temporarily overlap.) Digital video effects are an important subset of visual special effects. Zettl (1984) defined a digital video effect (DVE) as a "television visual effect [that] allows the creation of multi-images and the manipulation of the image size, shape, light and color, texture, and motion."

Zettl (1984) believed that visual special effects emphasize the graphic nature of the television screen and are used "to seduce us into perceiving the images of people, when they finally appear and move about normally on the screen, as real people rather than mere TV pictures" (p. 385). He warned that these various effects should not be used to camouflage insignificant content or badly shot or edited pictures, and may even have a profound impact on viewer perception. Zettl (1984) maintained, however, when properly used, many visual special effects can enhance production and help clarify and intensify the message of the program.

\section{Information Processing, Attention and Visual Special Effects}

According to the information-processing model of cognitive psychology, learning involves three interconnected systems: the sensory registers, which are involved in perception, and their corresponding memory structures; short-term memory; and long-term memory (Merriam $\varepsilon$ Caffarella, 1991). Understanding these systems can help producers use production principles that support learning.

Jacobsen $(1950,1951)$ determined that the eye was thirty times more efficient than the ear in transmitting information to the central nervous system. Indeed, Treichler (1967) stated that we learn 83 percent from sight, and remember 30 percent of what we hear, but 50 percent of what we see AND hear. Although theorists disagree about if and which sensory channels do a better job of processing new types of information (visual versus verbal primacy theory; Wood, 1984), it is clear that our visual senses play a large role in perceptive processes. However, there appears to be a limit to the amount of information that can be transmitted from any sensory register through the central nervous system (Spencer, 1988). A great deal of information is assimilated into sensory memory, but only a small portion is attended to and later recalled.

Attention is a control system that determines what is important enough to be moved into the short-term memory store (Merriam $\varepsilon$ Caffarella, 1991). Using selective attention, an organism can "choose" to process certain incoming stimuli over others. Attention also helps an organism decide how much and to what degree the incoming stimuli will be processed (Kahneman, 1973). 
Greer and Gibson: Visual Special Effects in Instructional Video Programs and Their

Kahneman's (1973) theory of attention is called capacity theory. He assumed that there is a general limit on the capacity or resources to perform mental work. Different mental tasks pose various demands on this limited capacity. When there is an insufficient supply of attention to meet cognitive demands, performance suffers or fails. Kahneman concluded that "novel and surprising stimuli [that] spontaneously attract attention also require a greater effort of processing than do more familiar stimuli" (p. 4).

Another important theoretical concept to consider when analyzing visual special effects is cross-channel interference. Visuals with competing audio (or vice-versa) create cross-channel interference that competes for attention and long-term memory storage. Hsia (1977) suggested that multi-channel presentations may be ineffective in terms of information recall due to the presence of crosschannel interference or the lack of between-channel redundancy, which he defined as the information two channels share with one another to a) reduce error to a tolerable level in information processing, b) lessen the effects of noise, interference and distortion, and c) reduce forgetting or memory decay. Hsia (1977) contended that the manipulation of redundancy is fundamental in communication. Therefore, attention, with its limited capacity, cannot be directed to process effectively all of the incoming complex visualization that accompany visual special effects. This limitation is especially true if the audio is not complementary.

\section{Television Cognitive Effects Research with Children}

Research on television effects in the 1950s and 1960s focused primarily on the influence of violence on children. During the early 1970 s, some psychologists shifted to other cognitive effects, such as the nature of attention to television and the role of formal features in generating attention and comprehension (Condry, 1989). This research began with children. Although it can be argued that adults are different from children in how they process television (Condry, 1989). the groundwork was laid by researching children and so that research will be considered here.

Formal features can convey information about central content by signaling what is important via visual and auditory devices (Condry. 1989). (As a "visual device," visual special effects are considered a formal feature.) According to Salomon (1979), watching television can be cognitively demanding. He suggested that certain formal features of programs, such as zooming in and out, represent mental skills that are learned from television and can be used in everyday problem solving. The varying degrees to which these elements are used can aid or interfere with information processing. The greater 


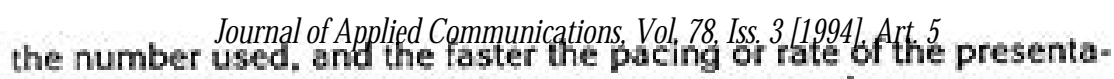
tion, the more complicated the message seems to be.

Critical questions at hand include: How much does learning via television depend on attention and comprehension, and if it does, what is the relationship between the two? How do the various production variables affect this relationship? Chu and Schramm (1967), Gagne (1980), and Stevenson (1972) determined that attention given to a television program is positively correlated with compre: hension. Much of the research demonstrates that there is a complex relationship between attention and comprehension (Huston $\varepsilon$ Wright, 1983). Huston and Wright believed that formal features may cue the attention of children to expend mental effort, which is defined as "the amount of mental capacity required to carry out a thinking task" (Gilbert \& Schleuder, 1990). Lorch, Anderson, and Levin (1979) and Zillmann, Williams, Bryant, Boynton, and Wolf (1980) found that visual attention to specific, critical segments of a program is important for learning. if content can be comprehended by the child.

Regarding visual attention, Watt and Welch (1983) stated, "If one desires to maximize [children's] learning by manipulating production techniques, it appears one should worry less about modifying visual attention levels and more about the direct effect of program form complexity on the memory processes of young viewers" (p. 98).

\section{Television Cognitive Effects Research with Adults}

As previously mentioned, in television research there is some evidence that there are basic differences in how adults and children process information (Condry, 1989). These differences are in part due to the manner in which children and adults process television conventions, or formal features, which is developmentally based (Huston \& Wright, 1983). Younger children, in particular, lack a variety of cognitive skills that are necessary for deep processing, as well as linguistic skills and world knowledge (Huston \& Wright, 1983). Therefore, it is important to look at television research that has been conducted with adults.

Morris (1988) conducted a study with college students using various production techniques (music, graphics, dramatic scenarios, etc.) to improve a "talking head" instructional videotape. Students' recall scores improved significantly after viewing tapes with enhanced production values compared to control group scores of students viewing the talking head program. However, this study merely proved that use of simple techniques, such as text graphics, enhances learning by visualizing a non-dynamic presentation. There was no analysis of the visual special effects that are more complicated or time-consuming to produce, such as DVE. 


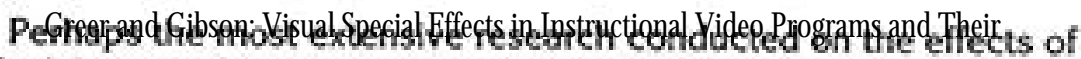
television visuals on adults has been in the area of news. Much of this research has shown that viewers of television newscasts recall little of the content. Graber (1990) cited the problems of measuring the information gain effects of pictorial complexity because of complications in researcher coding (researchers often cannot consistently code pictures that are constantly changing). Also problematic is the tendency for researchers to judge visuals primarily by what they contribute to verbal text, not by what they contribute indepen. dently (Graber, 1990).

Pictures can make information transmission more rapid, accurate, and realistic than is possible in purely verbal messages because they can provide more detail and a better grasp of relationships (Graber, 1988 ). But when watching television news viewers usually have little time to ponder what they are seeing, especially if they are simultaneously bombarded with verbal information that is often only partially redundant with pictorial information. Graber also postulated that the most valuable and attended to pictures in television news are the close-ups of people, which tend to involve viewers emotionally and allow them time to assess credibility through non-verbal actions. She discovered that viewers have less of a tendency to process visuals-as-abstractions (Graber, 1988).

Son and Davie (1986) found that the redundancy between pictures and audio significantly affects recall, but not understanding, of television news stories. They interpreted their results in light of Severin's cue summation theory (cited in Son $\varepsilon$ Davie, 1986), which suggests that the presentation of irrelevant cues in either audio or visual channel will cause a loss of learning from the other channel. Son and Davie hypothesized that dynamic visualizations might present irrelevant cues in either the visual or audio channels. This splitting of attention results in a loss of learning from the other channel. When such cross-channel interference occurs (i.e. there is little redundancy between channels), the visual channel often suffers because the viewer will pay more attention to the audio channel (Drew $\varepsilon$ Cadwell, 1985). When audio and visual information are complementary, however, greater overall learning will take place. For example, Baggett and Ehrenfeucht (1983) compared college students' encoding and retention of visual versus linguistic information and the presentation order of the visual and linguistic information in an educational film. This study showed that there is no competition for resources when related information is presented simultaneously in the visual and verbal/auditory channels. In addition, the researchers discovered that a good deal of linguistic information was encoded but half was lost in a week. Far less visual information was encoded, but all was retained for more than a week. 


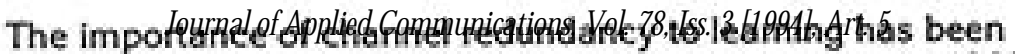
corroborated by many other studies (Miller, 1982; Nugent, 1982; Wember, 1976; cited in Heuvelman, 1989; Hartman, 1961; Woodall, Davis, \& Sahin, 1983; Severin, 1967; cited in Reese 1984; Reese, Drew, $\&$ Grimes; cited in Son $\&$ Davie, 1986).

Another area to consider in the area of visual special effects is form complexity, or the number and complexity of picture elements on the television screen. White (1983) examined the relationship between the form complexity of the television image and the capacity of the human processor to perform the function of identification and recognition. She coded television public service announcements for form complexity and tested subjects for recall on colors and background items after they had viewed the public service announcements as a primary activity while identifying letters flashed on the screen as a secondary activity. Her results showed that the scores for letter identification were lower as form complexity in. creased for the primary task, confirming capacity demand on the entire information processing system for identifying incoming stimuli. She concluded, "...highly complex visuals may not be ideal for learning purposes. This does not mean that such presentations may not be aesthetically pleasing or emotionally arousing. It simply means that they are not useful for conveying factual information that needs to be recalled" (p. 22).

Heuvelman (1989) conducted a number of experiments analyzing the cognitive effects of various visual formats of educational television programs. He worked with Knowlton's three types of visual representations-realistic, analogical, and logical (or schematic) pictures-and measured short-term as well as long-term memory effects. He found that the schematic visualizations were better than the realistic pictures and analogies in facilitating memory and concluded that simpler, less complex pictures facilitated short-term and long-term memory. This result contradicts Graber's conclusions about abstract visuals but corroborates White's findings.

In a recent experiment with college students, however, Gilbert and Schleuder (1990) compared a complex photo (a crowded street scene) with a simple one (a man's head and shoulders against a white background). They found that complexity improved image memorability. The authors concluded, "Emotional content, image design, and image meaning may interact with structural complexity factors in determining how well a photograph is processed and remembered" (p. 756).

Although not all of these studies agree, it appears that there is evidence that too much pictorial information, created by excessive form complexity, as well as interference between audio and visual 


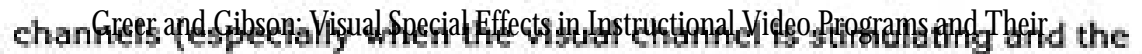
audio information is not redundant), may have a negative impact on memory and comprehension. However, other factors-such as image meaning-may overcome these forces and increase leaming.

\section{Research on Visual Special Effects and Adults}

There has been little research conducted directly on the effects of visual special effects in film or video, particularly with adults. However, two relevant studies will be mentioned here.

Goldstein (1985) examined the effects of another formal feature of television - editing (cuts and dissolves) - on learning from a television production. She found that undergraduate students scored significantly higher on six test questions relating to material that occurred immediately after a dissolve. However, this effect apparently disappeared after two questions. She theorized that this happened because the novelty effect of the dissolves quickly wore off, and students stopped paying extra attention to the material simply because it happened after a dissolve.

Perhaps the most relevant study on the instructional effect of visual special effects in adults-Ginsburg, Bartels, Kleingunther $\mathcal{E}$ Droege (1988) - found that college student recall scores diminished significantly after viewing elaborate abstract visual effects in the television program "Cosmos." Students were tested after viewing special effects coupled with information simultaneously presented in the aural channel via narration.

The authors theorized that the highly stimulating visual material interfered with the viewer's ability to process effectively information on the soundtrack only, thereby reinforcing the concept of crosschannel interference. This interference may have occurred because special effects differ from most reality-based visuals (e.g. newsreel footage, people-oriented commercials) in that they are abstract, novel, and complex in color, motion, space, and time.

However, Ginsburg et al. (1988) believed that special effects can entertain the viewer and hold attention, and therefore may make the viewer more likely to select such a program for subsequent viewing.

What does this all mean? Based on his meta-analysis of the research, Spencer (1988) summarized the literature:

[Although] multi-sensory presentations do seem to facilitate learning on specific tests, they do so only in circumstances where audio and visual components are mutually supportive.... Visual information also appears to be compressed by the processing system....This is necessary because of the limited capacity of the system and precludes any facilitating effects anticipated by increasing pictorial complexity or realism. (p. 137) 


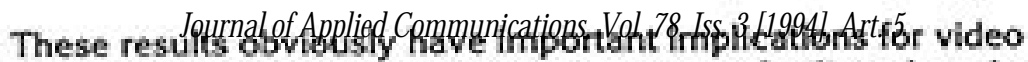
producers and instructional designers, who can facilitate learning by organizing material so that it is easily decoded while in short-term memory. Therefore, the amount and rate of information presented is a major concern in the design of television programs (Kozma, 1986).

\section{Conclusions}

In our information-rich Western society, people do try to economize on processing the plethora of data from the many sources that provide it (Graber, 1988). They must learn to do so in order to avoid information overload because of limited cognitive capacity. They seek information relief through television, possibly because they perceive it as less demanding than print (Salomon, 1983). What they may get instead is an overioad of another sort, which can exceed their attention capacity-excessive visualization through inappropriately designed visual special effects. As demonstrated by the existing literature, this overload is worsened by competing messages from the audio and textual channels.

Although some of the research results that can be applied to visual special effects and adult learning contradict one another, there appear to be areas of agreement:

1. Complementary visuals and audio increase learning. If visuals are abstract, however, they may interfere with information being presented simultaneously in the audio channel, especially if the audio channel is the only source of factual information.

2. Complex visuals may temporarily stimulate attention but probably do not increase learning in the long run. (Pictures of people may be the only exception.) On the other hand, overly simple visuals may bore some viewers and discourage their information processing.

New electronic techniques, such as visual special effects and computer graphics, allow us to develop our abilities in the communication arts. But because they are often novel, such devices can be overused. Educational television producers and designers can lose their perspective on their actual program goals: to communicate effectively and to instruct. In the end they often contribute to the information overload most westerners face each day.

Educational television producers and designers should carefully consider how viewers will process the information they are fashioning (Rieber, 1991). Audiences are different in how they will react to visual special effects and computer graphics (Salomon, 1983), and it is especially important that media professionals know enough about their audiences to determine the efficacy of the effects they use. 
Greer and Gibson:Visual Special Effects in Instructional Video Programs and Their

Virtually all of the studies that review adults point to problems of cross-channel interference with poorly-designed or superfluous visual special effects. In addition, visuals that are complex in form or more realistic tend to provide too much information and tax attention capacity. However, because there is such a limited number of studies, with few being replicated, it is clear that researchers need to collect additional data that will assist instructional designers and producers in making informed decisions about when to use visual special effects in their educational programs. There is much to be considered-not only the effects of these special visuals on learning but also on source credibility. For example, if an effect does not augment learning but makes the producer or producing agency seem more credible to the viewer, would it then be justified?

Another area for further consideration is performing research under more ecologically valid conditions, and with bona-fide adults. There is some contention as to who is considered an adult learner. Many adult learning theorists (Cross, 1981) contend that it is not necessarily the traditional undergraduate college student, the source of most of the research on television's cognitive effects on adults. As Wood (1984) stated, "Studies of production variables have been generally too limited in their selection of subjects...empirical conclusions about people in general based on data collected from college students are tenuous at best and misleading at worst" (p. 73).

Although methodology and interpretations might be problematic, to understand better how to design educational television for adults, it is essential to conduct studies with learners who have families and full-time jobs. Perhaps the workplace might be a good venue for such research; even better, the home, where competing demands on processing television information might be at their highest.

Researchers also need to look at viewers with different characteristics. Berry (1982) argued that learner characteristics and production variables must be considered at all times in designing instructional material. Included in learner characteristics are viewers' learning styles and their reactions to special effects. There is some evidence that "visual" learners will attend more readily to and more easily process visual special effects (Tolomeo, 1985).

In reviewing the literature, the author finds it clear that not only are there problems with the subjects studied in television research in terms of learning, but there are also problems in how subjects are tested: via information gain, recognition, retention, and recall. Researchers tend to get conflicting results if they test recall versus recognition (Brosius, 1989; Watt \& Welch, 1983). Brosius (1989) based his views on his research that illustrated television news items do not necessarily lead to deeper processing and therefore higher 
Journal of Applied Communications, Vol. 78, Iss. 3 [ 1994], Art. 5

levels of learning. He surmised, "Recognition of details and memory for mere topics are only vague indicators of learning" (p. 10).

Wood (1984) described a significant problem with many studies on production variables: intervening variables are often unwittingly introduced. For example, a researcher studying television image size may also end up analyzing editing and pacing. How are we to interpret research results in these situations when interaction effects are not accounted for? Clearly, experimental designs must be carefully crafted to minimize these variables.

Graber (1990) also noted that it is unlikely that information processing is the same for all areas of knowledge. Experimentation with similar visual effects research in different content areas might prove fruitful. Such experimentation could help alleviate criticisms associated with information processing theory, specifically that "...it does not deal with the contextual or personal factors affecting an individual's channel capacity" (Littlejohn, 1989, p. 51).

Researchers could investigate a variety of visual special effects and test how they increase adult learning and comprehension of (a) specific content, (b) particular information processing contexts, and (c) audiences with particular learner characteristics. Clearly, instructional production decisions based on sound, multi-disciplinary theories and research, rather than intuition, will prove more effective in the long run for producers, educators, and learners.

\section{References}

Abed, F. (1988). The role of visual design in educational technology programs: The critical link. Educational Technology. 28(7), 43-44.

Baggett, P., E Ehrenfeucht, A. (1983). Encoding and retaining information in the visuals and verbals of an educational movie. Educational Communications and Technology Journal, 31(1), 23-32.

Berry, C. (1982), Research on television news. Bulletin of the Brilish Psychological Soclety, 35, 301-304.

Brosius, H.B. (1989). Influence of presentation features and news content on learning from television news. Journal of Broadcasting \& Electronic Media, $33(1), 1.14$.

Brush, D., \& Brush, J. (1993). The fifth Brush report: User-driven communication systems. La Grangeville, NY: HI Press.

Chu, G., E Schramm, W. (1967), Learning from television: What the research says. Washington, D.C.: NEAB

Condry, J. (1989). The Psychology of Television. Hillsdale, NJ: Lawrence Erlbaum Associates, Ine.

Cross, K.P. (1981). Aduits as leamers. San Francisco: Jossey-Bass.

Drew, D.G., \& Cadwell, R. (1985). Some effects of video editing on perceptions of television news, Joumalism Quarterly, (62), 828-831, 849.

Gagne, R.M. (1980). Is educational technology in phase? Educational Technology, 2042), 7-14,

Gayeski, D. (1991). Corporate $\mathcal{E}$ instructional videa Englewood Cliffs, NJ: https://newtice: Holll, Inciriepress.org/jac/vol78/iss3/5

DOI: 10.4148/1051-0834.1412 Oournal of Applied Communications, Vol. 78, No. 3, 1994/47 12 
Geber, Greer andGgibsgn:Visual Special Effects in Instructional Video Programs and Their

Gilbert, K.. \& Schieuder, J. (1990). Effects of color and complexity in still photographs on mental effort and memory. Sournalism Quarterly, 67, 749-756.

Ginsburg. H., Bartels, D.. Kleingunther, R., E Dreege, L. (1988). Cosmos revisited: Just how effective are special effects for instructional communication? Interna. tional Joumal of Instructlonal Medla, 15(4), 319-326.

Goldstein, W. (1985). The effect of cuts and dissolves on time perception, recall of edits, leaming from and reactions to a televison presentation. Unpublished master's thesis, University of Wisconsin, Madison.

Graber, D. (1988). Processing the news: How people tame the information tide (2nd ed.). New York: Longman, Inc.

Graber, D. (1990). Seeing is remembering: How visuals contribute to leaming from television news. Journal of Communicatlon, 40(3), 134-155.

Hanson, L (1989). Multichannel learning research applied to principles of televi. sion production: A review and synthesis of the literature. Educational Technol. ogy, $29(10), 15 \cdot 19$.

Harder, C. (1985). Specific production vartables used in the design of instructional television and their effects on tearning. Unpublished master's thesis, University of Wisconsin, Madison.

Heuvelman, A. (1989). Cognitive effects of different visual formats in an educational television-programme. Communication and Cognition, 22(1), 61-71.

Hsia, H.J. (1977). Redundancy: Is it the lost key to better communication? AV Communication Review, 25, 63-81.

Huston, A.C., \& Wright, J.C. (1983). Children's processing of television: The informative functions of formal features. In J. Bryant $E$ D.R. Anderson (Eds.). Children's understanding of television: Research on attention and comprehen. sion (pp. 35-68). New York: Academic Press.

Jacobsen, H. (1950). The information capacity of the human ear. Science, 112 , 143.144.

Jacobsen, H. (1951). The information capacity of the human eye, Science, 113, 292-293.

Kahneman, D. (1973). Attention and effort. Englewood Cliffs. NJ: Prentice-Hall.

Kozma, R. (1986). Implications of instructional psychology for the design of educational television. Educational Communications and Technology foumal, 34(1), 11-19.

Littlejohn, S.W. (1989). Theories of human communication (3rd ed.). Belmont. CA: Wadsworth Publishing Company, Inc.

Lorch, E.P., Anderson, D.R., \& Levin, S.R. (1979). The relationship of visual attention to children's comprehension of television. Child Development, 50 , 722-727.

McCartney, C. (1990, April). The effects effect. Video Systems, pp. 54-58.

Merriam, S.B., \& Caffarella, R.S. (1991). Learning in adulthood. San Francisco: Jossey-Bass.

Metallinos, N. (1991). Perceptual factors in the study of television aesthetics. Montreal, Canada: Concordia University. Department of Communication Studies. (ERIC Document Reproduction Service No. ED 343 172).

Morris, J. (1988). The use of television production techniques to facilitate the learning process: An experiment. International fournal of Instructional Media. $15(3) .244-256$.

Reese, S.D. (1984). Visual-verbal redundancy effects on television news learning. Journal of Broadcasting. 28(1), 79-87.

Rieber, L.P. (1991). Effects of visual grouping strategies of computer-animated presntations on selective attention in science. Proceedings of Selected Research 


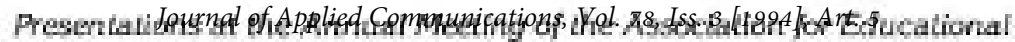
Communications and Technology, 5-15.

Salamon, G. (1979). Interaction of media, cognition, and learning. San Francisco: Jossey-Bass.

Salamon, Q. (1983). Television watching and mental effort: A social pscyhological view. In J. Bryant E D.R. Anderson (Eds.), Children's understanding of televislon: Research on attention and comprehensian (Pp, 181. 198). New York: Academic Press.

Seels, B. (1989). The instructional design movement in educational technology. Educatlonal Technology. 29(7), 11-15.

Shiffman. S.S. (1986). Instructional systems design: Five views of the field. Journal of instructional Development, $9(3), 14-21$.

Smith, D.L. (1991). Video communication. Belmont, CA: Wadsworth Publishing Company.

Son, J., E Davie, W. (19B6, August). The effects of visual-uerbal redundancy and recaps on television news learning. Paper presented at the annual conference of the Association for Education in Journalism and Mass Commu. nication, Norman, OK.

Spencer, K. (1988). The psychology of educational technology and instructional media. London: Routledge.

Stevenson, H.W. (1972). Television and the Behavior of Preschool Children. Television and social behavior: Television and social leaming. Washington, DC: U.S. Govemment Printing Office.

Tolomeo, M. (1985). Influence of audience varlables on the meaning and appreciation of spectal effects in small format oideo. Unpublished master's thesis, Cornell University, Ithaca, NY.

Treichler, D.G. (1967). Are you missing the boat in training aids? film and $A V$ Communication, I, 14-16.

Walker, J.R. (1987). Persuasive impact of production techniques: Previous research and future directions. Feedback, 28(3), 11-16.

Watt, J.H., Jr., \& Welch, A.J. (1923). Effects of static and dynamic complexity on chlldren's attention and recoll of televised instruction. In J. Bryant \& D.R. Anderson (Eds.). Children's understanding of television: Research on attention and comprehension (pp. 69-102). New York: Acodemic Press.

White, S.E. (1983, May). The effect of form complexity of television an the identification/recognition process. Paper presented at the Annual Mceting of the International Communication Association, Dallas, TX.

Whiting, $\mathrm{L}$. (1988). The television renaissance in extension education. Lifelong Learning. 1$](8), 19-22$.

Wood, S.C. (1984). The effects of production variables in television: A developmental theory (Doctoral dissertation, University of Maryland College Park, 1984). Dissertation Abstracts international, 46. 02A.

Wurman, R. S. (1989). Information anxiety: What to do when information doesn't tell you what you need to know. New York: Doubleday.

Zettl, H. (1984). Television production handbcok. Belmont, CA: Wadsworth Publishing Company.

Zilmann, D., Williems, B.R., Bryant, J., Boynton, K.R., E Wolf, M.A. (1980). Acquisition of information from educational television programs as a function of differently paced humorous inserts. Joumal of Educational Psychology. $72,170-180$. 